\title{
CARACTERÍSTICAS DO BULLYING COMO UM TIPO DE ASSÉDIO MORAL NAS ORGANIZAÇÕES
}

\author{
CHARACTERISTICS OF BULLYING AS A TYPE OF MORAL HARASSMENT IN ORGANIZATIONS
}

DOI: http://dx.doi.org/10.12712/rpca.v5i1.22

\author{
Ana Luísa Nogueira Marcondes \\ Universidade Presbiteriana Mackenzie - SP \\ Reinaldo Dias \\ Universidade Presbiteriana Mackenzie - SP. Centro Universitário UNA - MG
}

\section{RESUMO}

Este artigo tem como objetivo analisar o fenômeno assédio moral nas empresas e identificar a prática do bullying como uma de suas dimensões, caracterizado pela conduta abusiva do superior hierárquico em relação a seu subordinado. Para tanto examinamos o conceito de assédio moral, mobbing e bullying e sua relação com as pressões para o aumento da produtividade e eficiência nas organizações. Com os dados obtidos pela pesquisa, tecemos as considerações finais tendo como expectativa contribuir para uma visão do fenômeno a partir da perspectiva dos sujeitos envolvidos (assediadores e vítimas) e quais as estratégias que devem ser desenvolvidas pelas empresas para evita-lo, através de intervenções mais eficazes e que devem não só estar dirigidas aos envolvidos diretamente, mas também considerando o contexto onde é gerado esse tipo de comportamento agressivo.

Palavras-chave: Assédio moral. Bullyng. Mobbing. Empresas. Produtividade.

\begin{abstract}
This article aims to analyze the phenomenon of moral harassment in companies and identify bullying as one of its dimensions, characterized by improper conduct of the superior in relation to his subordinate. For that, we examine the concept of moral harassment, mobbing and bullying and its relation to pressures for increased productivity and efficiency in organizations. With the data obtained by the survey, we make final remarks expecting to contribute to a vision of the phenomenon from the perspective of those involved (victims and harassers) and which strategies should be developed by companies to avoid it, through interventions that are more effective and that should be directed not only to those directly engaged, but also considering the context where that kind of aggressive behavior is generated.
\end{abstract}

Keywords: Moral harassment. Bullying. Mobbing. Companies. Productivity. 



\section{INTRODUÇÃO}

As pesquisas sobre a incidência do fenômeno do assédio moral em locais de trabalho no Brasil colocam de imediato que estas situações são comuns nas empresas e ocorrem desde muito tempo, embora tenham se intensificado nos últimos anos.Atualmente tem aumentado o interesse, gerado em parte, pela maior exposição midiática de alguns casos mais alarmantes, que sem dúvida tem contribuído para o aumento do conhecimento e a uma maior conscientização sobre a gravidade do problema.

Embora os temas de interesse associados sejam diversos, podemos afirmar que a atitude daqueles com nível hierárquico superior se constitui num dos aspectos mais preocupantes e que merecem uma análise mais detalhada, em virtude de terem um maior grau de identificação com a empresa, o que remete a avaliação do nível de responsabilidade das organizações na facilitação (ou até mesmo indução) desse tipo de comportamento.

De fato, diferentes aspectos do contexto social no interior das empresas contribuem para o surgimento e manutenção de situações de assédio moral. Nesse contexto é que adquirem relevância os diferentes estilos de direção aceitos e incentivados nas organizações. Nessa perspectiva se deve assumir que o problema adquire bastante complexidade e amplas repercussões, que além de afetar os sujeitos envolvidos diretamente (assediador e vitimas), repercute negativamente no clima organizacional e de convivência da empresa. Assim, a partir de uma perspectiva multidimensional do fenômeno assédio moral, é necessário focar a pesquisa na relação existente entre os diversos fatores sociais que favorecem ou reforçam as situações de agressividade no local de trabalho.

Com esse propósito a pesquisa foi sendo desenvolvida, e da qual a principal contribuição que se espera é oferecer uma visão do fenômeno a partir da perspectiva dos sujeitos envolvidos (assediadores e vitimas) e das estratégias das empresas num contexto de aumento da competição e da necessidade de cumprimento das metas em prazos cada vez mais exíguos.

Pretende-se, em última instância, entender de uma forma mais específica a complexidade do fenômeno e os diferentes fatores que podem estar incidindo sobre ele; de tal modo que contribua para traçar estratégias de intervenção mais eficazes e que devem não só estar dirigidas aos envolvidos diretamente, mas também considerando o contexto onde é gerado esse tipo de comportamento agressivo. Tendo esse objetivo em mente foi desenvolvida a pesquisa, da qual são expostos neste artigo alguns resultados obtidos.

\section{A COMPLEXIDADE DO ESTUDO DO ASSÉDIO MORAL NAS EMPRESAS}

O fenômeno do assédio moral no ambiente de trabalho está se convertendo em um tema cada vez mais frequente no noticiário na medida em que aumenta a competição entre as empresas e em decorrência as pressões internas para aumento da produtividade. Trata-se de um comportamento social relacionado ao maltrato físico ou verbal sistemático por parte de um ou mais indivíduos contra outro.

No dicionário Houaiss (2001) o termo assédio é definido como a "insistência impertinente, perseguição, sugestão ou pretensão constantes em relação a alguém” e o verbo assediar significa "perseguir com propostas; sugerir com insistência; ser importuno ao tentar obter algo; molestar".

A associação do termo "moral" com a palavra "assédio" deve-se a Marie-France Hirigoyen que considerou que estas ações se encontram no campo da ética ou da moral.Para ela, escolher o termo moral implica numa tomada de posição, pois "trata-se efetivamente de bem e de mal, do que se faz e do que não se faz, e do que é considerado aceitável ou não em nossa sociedade", não sendo "possível estudar esse fenômeno sem se levar em conta a perspectiva ética ou moral". (HIRIGOYEN, 2006, p. 15)

O Assédio Moral no ambiente de trabalho está associado a insistência, constância no comportamento do molestador, não se tratando de ações eventuais.

Um indivíduo é assediado, tornando-se vitima, quando está exposto de modo repetitivo a ações 
negativas por parte de uma ou mais pessoas. As ações negativas são comportamentos agressivos visando atingir e molestar a outra pessoa. Essas ações podem ser realizadas através de contato físico, verbal ou de outros modos como fazer gestos depreciativos e que envolvem sempre a exclusão intencional do individuo do ambiente coletivo. É um tipo de relação que somente ocorre porque há um desequilíbrio de poder ou de força, ou seja, uma relação assimétrica.

As atividades de assédio moral são sistemáticas e recorrentes, nunca se tratam de ações isoladas; se tratam de ações articuladas e concatenadas com um propósito bem definido que é isolar a vitima, destruir sua reputação, quebrar suas redes de comunicação, perturbar seu cotidiano no trabalho e violentar sua personalidade e dignidade degradando-a até o limite de conseguir que a vitima se encontre totalmente indefesa e incapaz de reagir.

Uma das definições mais utilizadas é a de Marie-France Hirigoyen segundo a qual o assédio moral no trabalho pode ser definido como

\begin{abstract}
"qualquer conduta abusiva(gesto, palavra, comportamento, atitude...) que atente, por sua repetição ou sistematização, contra a dignidade ou integridade psíquica ou físicade uma pessoa, ameaçando seu emprego ou degradando o clima de trabalho".(HIRIGOYEN, 2006, p. 17)
\end{abstract}

A Organização Internacional do Trabalho(OIT) editou em 2002 uminforme com as condutas mais comuns e que configuram o assédio moral. Dessa relação constam(NASCIMENTO, 2009, p. 34):

a) Ações que tem por objetivo excluir uma pessoa da sua atividadeprofissional;

b) Contínuos e persistentes ataques negativos ao rendimento pessoal ou profissional sem nenhum motivo;

c) Difusão de rumores e o desenvolvimento de ações que visam a ridicularização com o objetivo de prejudicar a reputação pessoal ou profissional de uma pessoa;

d) Exercício abusivo do poder com a adoção de práticas tais como: menosprezo persistente do trabalho realizado pela pessoa, fixação de prazos inatingíveis ou pouco razoáveis e atribuição de tarefas impossíveis;

e) 0 controle desmedido ou inapropriado do rendimento de uma pessoa.

0 assédio moral, em síntese, constitui-se num comportamento agressivo que visa prejudicar a outro intencionalmente; é executado de forma repetitiva e inclusive fora do ambiente de trabalho e constitui-se numa relação interpessoal que se caracteriza por um desequilíbrio real ou superficial de poder.

O assédio moral tem várias denominações adotadas em diferentes países como: Bullying, Bossing, Harassment(na Inglaterra, Austrália e Irlanda), Harcélement moral (Assédio moral, França), Murahachibu(Ostracismo social) e Ijime(assédio, Japão), Acoso laboral, Acoso moral acoso psicológico e psicoterrorismo(países de língua espanhola),mobbing (países do norte da Europa e Estados Unidos) entre outras denominações(GUIMARÃES E RIMOLI, 2006; ALKIMIN, 2010; HIRIGOYEN, 2006; SCHATZMAN etall, 2009; LIMA Fo., 2009). Deve-se levar em consideração, ainda, que o local onde é utilizada cada denominação varia muito, pois com a facilidade de comunicação, via internet, termos localizados podem se disseminar com com rapidez, extrapolando seu local de origem original, como é o caso de bullying e mobbing que são utilizados no Brasil, além de Assédio Moral. 0 fato é que qualquer que seja a definição adotada, o que importa é que o

“assédio moral é uma violência sub-reptícia, não assinalável, mas que, no entanto, é muito destrutiva. Cada ataque tomado de forma isolada não é verdadeiramente grave; o efeito cumulativo dos micro-traumatismos frequentes e repetidos é que constitui a agressão"(HIRIGOYEN, 2006, p. 17). 
Entre as várias denominações associadas a assédio moral no trabalho mencionadas,as

mais adotadas são mobbing e bullying.

0 termo mobbing é originado do verbo inglês tomob que tem o significado de maltratar, atacar, perseguir, sitiar. 0 substantivo mob pode ser traduzido como multidão ou turba, com letra maiúscula, Mob significa máfia. A origem do termo demonstra que se trata de um fenômeno essencialmente de grupo (HIRIGOYEN, 2006, p. 77)

A definição de mobbing no local de trabalho foi introduzida por Heinz Leymann nas décadas de 1980 e 1990principalmente em seus trabalhosMobbingandPsychological Terror atWorkplaces (1990)"The contentanddevelopmentofmobbingatwork"(1996). Leymann caracteriza o mobbing como envolvendo comunicação hostil e imoral, que é dirigida de modo sistemático por um ou alguns indivíduos, principalmente direcionados a um indivíduo que, devido ao assédio fica indefeso, sendo mantido nesse estado para fins de permanência do molestamento. Segundo ele, essas ações ocorrem com frequência e por um longo período de tempo.(LEYMANN, 1990, p. 120;1996, p. 168). Leymann optou pela não utilização da palavra bullyingnos locais de trabalho por considerar que o termo se identifica mais com agressão física e ameaça, sendo que o mobbing é caracterizado por um comportamento mais sofisticado, como por exemplo o isolamento da vitima(LEYMANN, 1996, p. 167). Sugeriu ainda a utilização da palavra bullying para o comportamento das crianças e adolescentes e o termo mobbing para o de adultos (idem, p. 167).

0 termo bullying tem origem na palavra inglesa tobully, que significa tratar com desumanidade, com grosseira; o bully (ou bullie) é uma pessoa grosseira, um valentão, de comportamento tirânico e que ameaça os mais fracos (HIRIGOYEN, 2006; p. 78- 79).

O termo bullying, inicialmente, era mais utilizado para descrever as humilhações, os vexames ou as ameaças que determinadas crianças ou grupos de crianças infligem a outras. Posteriormente o termo se estendeu a agressões observadas em outros ambientes sociais, inclusive nos locais de trabalho(HIRIGOYEN, 2006; p. 79).

Embora haja autores que considerem que mobbinge bullying apresentam o mesmo conteúdo, entendemos que há diferenças entre os dois termos, como já identificado porHirygoyen(2006, p. 80) que cita DieterZapf(1999) segundo o qual bullying é originário majoritariamente de superiores hierárquicos, enquanto o mobbing é muito mais um fenômeno de grupo, diferenciação que a autora está de acordo.

A pesquisadora francesa menciona que os termos mobbing e bullying não são idênticos embora sejam frequentemente utilizados indistintamente, no entanto o "termo mobbing relaciona-se mais a perseguições coletivas ou à violência ligada à organização"; já o termo bullyng é mais amplo , "vai de chacotas e isolamento até condutas abusivas com conotações sexuais ou agressões físicas. Refere-se mais às ofensas individuais do que á violência organizacional" (HIRIGOYEN, 2006, p. 85).

Esse também é o entendimento de Marcia Novaes Guedes em seu livro "Terror psicológico no trabalho" no qual considera que mobbing diferencia-se do bullying e do bossing porque tais termos expressam o autoritarismo decorrente do abuso de poder de alguns chefes. (GUEDES, 2005).

Outra autora , Hádassa Ferreira é ainda mais precisa, considera o mobbing e o bullying duas visões diferente do mesmo fenômeno. Considera que o mobbing "consiste no assédio moral instalado em uma relação simétrica, isto é, entre os próprios colegas de trabalho, que não necessariamente estejam em uma relação hierárquica". Quanto ao bullying julga que "é mais facilmente percebida em relações assimétricas, nas quais existe uma hierarquia, sendo presentes as figuras do superior hierárquico e do empregado encarregado" (FERREIRA,2010, p. 58).

Neste trabalho o termo bullyingé identificado com as ações individuais originadas de alguém com poder superior, que agride outro inferiorizado ou subordinado. E o termo mobbing será identificado 
com as ações de grupos agindo sobre um ou mais indivíduos inferiorizados, que são molestados sistematicamente.Nesse sentido, podemos identificar no ambiente de trabalho a existência tanto do mobbing, quanto do bullying, sendo ambos formas de assédio moral.

\section{OS DIFERENTES TIPOS DE ASSÉDIO MORAL}

Como a maior parte dos autoresidentifica três tipos básicos de assédio, levando-se em consideração a direção em que é realizado: horizontal e vertical ascendente ou descendente (GUIMARÃES E RIMOLI, 2006; ALKIMIN, 2010; SOUZA, 2009; GUEDES, 2005;THOME, 2009) devemos, primeiramente, identificar e tipificar o bullyingnas organizações levando em consideração esses modelos reconhecidos. Assim temos que:

a) 0 assédio moral horizontal é o que ocorre entre os empregados em relação a outro companheiro de trabalho, se origina quando um grupo explora pessoas frágeis do ponto de vista psíquico ou físico sem um motivo aparente visando passar o tempo ou simplesmente proporcionar aborrecimentos. Este tipo de assédio moral se identifica também com mobbing, pela não identifica clara de um agressor e a participação difusa, mas persistente dogrupo.

b) Considerando o assédio moral vertical ascendente ou descendente temos uma diferenciação mais objetiva. 0 vertical ascendente é quando uma pessoa que pertence a um nível hierárquico superior da organização é molestada por um ou vários subordinados. É um tipo de assédio que se origina quando alguém de fora da empresa assume um cargo superior e, por qualquer motivo não é bem aceito pelos trabalhadores; ou sua origem pode ser encontrada em situações em que os chefes assumem posturas autoritárias e arrogantes nos contatos interpessoais. É um tipo de assédio moral menos comum e de acordo com o exposto anteriormente trata-se de mobbing, pois não há claramente um assediador e se identifica claramentecom as origens do termo mobbing.

c) No caso, inverso, o assédio moral vertical descendente pode ser caracterizadoquando o chefe é o assediador, e persegue sistematicamente um funcionário, nesse caso o assédio de um "bullie" é evidente tratando-se do superior na estrutura burocrática da empresa, este se valendo de seu poder hierárquico para molestar a vitima, seja por motivo próprio ou atendendo às pressões da organização.Trata-se neste caso de bullying, pois o molestador é perfeitamente identificado. É uma situação mais comum, também conhecida por bossing ( do inglês boss = chefe) e praticada por pessoas que detém algum poder e que desenvolvem ações insultuosas e ofensivas visando a desestruturar psicologicamente o assediado. Inclui-se aqui também a estratégia empresarial de forçar a saída do empregado, sem recorrer a sua demissão legal, trazendo vantagens para a empresa que não arcaria com os custos dessa operação.

O bullying nas organizações, portanto, pode ser caracterizado pela ação empreendida pelo superior hierárquico em relação a um subordinado, seja por motivo próprio ou atendendo ás determinações da empresa, por exemplo, visando a saída do empregado sem custos para a organização. Diferentemente do bullying que ocorre entre crianças e adolescentes, a assimetria de poder ocorre em função da estrutura organizacional burocrática, que legitima também uma estrutura hierárquica de poder, funcional na maior parte do tempo e que só facilita o assédio (bullying) quando é desvirtuada pelos ocupantes que se valem da condição de superioridade formal para molestar a outro.

\section{CARACTERIZANDO O BULLYING NAS ORGANIZAÇÕES}

O bullying nas organizações pode ser definido como um fenômenos social, que surge no local de trabalho, e que consiste num ataque sistemático de uma pessoa a outra, à sua dignidade e integridade física e/ou moral, com um objetivo, a auto-exclusão da vitima. Essa ação empreendida pelo agressor é favorecida pela existência de uma assimetria de poder.

Max Weber, em sua obra Economia e Sociedade, conceituou poder que no seu entender "significa toda probabilidade de impor a própria vontade numa relação social, mesmo contra resistências, seja qual 
for o fundamento dessa probabilidade" (WEBER, 1991, p.33).

Uma definição de poder elaborada por Robert Dahl, inspirado em Weber, tornou-se clássica nos estudos organizacionais. Segundo ele: "o poder de uma pessoa A sobre uma pessoa B é a capacidade de A de obter que B faça algo que não teria feito sem a intervenção de A(DAHL,1957,p.202).

0 exercício do poder, através de diversos mecanismos, para conseguir que as condutas das pessoas que trabalham estejam de acordo com os parâmetros previamente estabelecidos, é uma prática legitima no mundo do trabalho. Há sempre algum determinado nível de conflito com origem na adaptação a novos papéis, do exercício de direção ou divergência de interesses e que integra o conjunto de inter-relações que se estabelecem em qualquer local de trabalho. No entanto, isto não pode servir de justificativa para o encobrimento de determinadas práticas que ultrapassam os limites de tolerância ou admissibilidade.

Há dois aspectos importantes a serem considerados quando relacionamos poder e bullying. Primeiro quem detém poder tem capacidade de exercer influência, e numa situação de assédio, esta capacidade se exerce e impede a possível resposta de enfrentamento ao assediador por parte da vítima, sendo esta atitude substituída por uma reação de evitar qualquer confronto, ou seja, de fuga. Em segundo lugar, se estabelece uma relação de dependência de uma das partes em relação àquela que exerce o poder. Esta relação de dependência ocorre devido ao controle que o assediador exerce sobre os recursos que a pessoa, que é alvo do molestamento, necessita.

0 poder do assediador se assenta, pelo menos, em quatro bases: a coerção, concessão de benefícios, capacidade persuasiva e conhecimento.

A coerção está baseada no medo da vitima que teme as consequências negativas da desobediência, assim se submete a ameaças, sanções e se frustra constantemente ao não alcançar seus objetivos. A não concessão de benefícios, o bloqueio ao desenvolvimento profissional são outros instrumentos de assédio. A concessão ou manipulação de prêmios simbólicos, a capacidade de decisão e da manipulação da informação constitui o poder de persuasão do agressor. E finalmente, o conhecimento que se baseia no controle da informação necessária para a tomada de decisões na organização.

\section{A PESQUISA}

A pesquisa bibliográfica utilizou matérias publicadas nos jornais de grande circulação nacional (Folha de São Paulo, o Estado de São Paulo; o Globo) e, secundariamente em jornais regionais( Correio Popular, de Campinas).0 período abrangido pela pesquisa foi de 2006 a 2010 sendo selecionados os casos de maior repercussão e que tramitaram no judiciário.

\section{DISCUSSÃO E ANÁLISE DE DADOS}

A pesquisa encontrou um conjunto de ações empreendidas por agentes identificados como agressores e o comportamento das vitimas, formando uma síntese de casos que configuram práticas de bullying nas organizações. Os exemplos de assédio moral são muitos no Brasil, em sua maioria ocorrem devido ao não cumprimento das metas estipuladas. Muitas das metas são colocadas de maneira abusiva ou impossível de serem realizadas. As punições e castigos impostos aos empregados além de abusivos colocam as pessoas em situações desumanas deixando cada vez mais, o funcionário inseguro.

A pesquisa constatou que as práticas de assédio moral no interior das empresas ocorrem de diversas maneiras, tendo todas elas o mesmo objetivo, expor o funcionário ao ridículo, em situações vergonhosas e ferindo a dignidade e integridade física dos mesmos.

Alguns exemplos de práticas mais comuns:

a) Insultos, palavrões e maus tratos

Em empresa coreana da área de informática, situada no interior de São Paulo (Taubaté), estava 
disseminada a prática de utilização de insultos, palavrões e maus tratos, incluindo a agressão com tapa nas costas sofrida por funcionária. (PACHECO, 2010)

Outra empresa coreana, de outra cidade de São Paulo (Campinas), também da área de informática também foi denunciada pela existência de prática de assédio moral. Na unidade da empresa foram relatados casos em que os supervisores chamavam a atenção dos funcionários aos gritos e palavrões, além de casos de agressão física. Durante a diligencia do Ministério Público do Trabalho na empresa foi constatada a prática de jornada excessiva e forte pressão exercida sobre os trabalhadores para o cumprimento das metas de produção, com a afixação de placas e painéis por toda a fábrica. (MAGALHÃES, 2010)

\section{b) Humilhação}

Numa grande empresa de telefonia, uma supervisora, para incentivar os operadores, subordinados a ela, a cumprir as metas estipuladas, obrigava àquele que não as atingissem a vestir-se de palhaço, caipira e outras fantasias. Alegrar a equipe era a determinação do gerente, obrigando então que seus funcionários se expusessem às ironias dos colegas. (ZULINO,2008)

Em grande empresa do ramo de bebidas a humilhação também foi utilizada como forma de punição por não atingir as metas estipuladas. Em "reuniões motivacionais" eram adotadas as medidas punitivas para aqueles que não atingiram os objetivos entre essas se encontram: fazer flexões, polichinelos, safanões, tapas, gravatadas e xingamentos.0 empregado chegou a receber a punição com o chefe pisando-lhe nas costas. A empresa foi condenada a pagar indenizações. (JUSTIÇA, 2006)

\section{c) Agressão verbal}

Em outra empresa de telefonia um gerente chamava a funcionária de "incompetente e burra" e ainda acrescentava que "qualquer idiota as atingiria" ações empreendidas devido ao não cumprimento das metas estipuladas. A empresa foi condenada a pagar indenização á ex funcionária (JUNQUEIRA, 2009).

Num grande Banco na Bahia, um homossexual, era discriminado pelo seu superior imediato que o agredia chamando-o de "veado" e "bicha", além de submetê-lo a situações constrangedoras. A empresa foi condenada a pagar indenização. (FARIAS, 2009)

\section{CONCLUSÃo}

A pesquisa mostrou que as práticas adotadas de assédio moral nas grandes empresas brasileiras, em sua maioria, estão associadas às pressões para o aumento da produtividade e aumento da eficiência. A preocupação constante das chefias esta voltada para atingir as metas estabelecidas a qualquer custo. 0 não cumprimento desses objetivos tem implicado, em alguns casos, à utilização do assédio moral para desqualificar moralmente aqueles que não cumprem o que foi determinado. Foi identificado um aumento da frequência no noticiário de casos de abuso nos últimos cinco anos, o que pode estar relacionado com o desenvolvimento acelerado pelo qual vem passando o país. Novas pesquisas podem ou não confirmar esta suposição que não foi objeto principal deste trabalho.

Evidenciou-se na pesquisa a pressão que recebem os supervisores e gerentes para que suas equipes atinjam as metas estabelecidas pela alta direção. Como muitas delas são difíceis de serem cumpridas, os quadros dirigentes intermediários passam a pressionar aqueles que lhe são subordinados, muitas vezes com abuso de poder e em muitos casos facilitando o surgimento de personalidades ocultas, em outras circunstancias, que revelam uma índole próxima à de sociopatas, como alguns exemplos demonstraram neste artigo. 


\section{REFERÊNCIAS BIBLIOGRÁFICAS}

ALKIMIN, Maria A. Assédio moral na relação de trabalho. 2 e. Rev. e atual. Curitiba: Jurá, 2010.

DAHL, Robert. The concept of power. Behavioral Science, v. 2, p. 201-215, 1957.

FARIAS, Carolina. Justiça condena Bradesco a indenizar em R\$1,3 milhão exfuncionário por homofobia. Folha online. 22 Abril 2009. Disponível em: http://www1.folha.uol.com.br/folha/cotidiano/ult95u554602.shtmlacesso em 20 ago 2009.

FERREIRA, Hádassa D.B. Assédio moral nas relações de trabalho. Campinas: Russel Editores, 2010.

GUEDES, Márcia Novaes.Terror psicológico no trabalho. São Paulo: LTC, 2005

HIRIGOYEN, Marie-France. Mal-estar no trabalho: redefinindo o assédio moral. Rio de Janeiro: Bertrand Russer, 2006.

HOUAISS, Antonio e VILLAR, Mauro de Salles. Dicionário Houaiss da Língua Portuguesa. Rio de Janeiro: Objetiva, 2001.

JUNQUEIRA, Livia W. Terceirizada chamada de 'burra' leva indenização. O globo. 07 ago 2009. Disponível em: http://oglobo.globo.com/economia/seubolso/mat/2009/08/07/terceirizadachamada-deburra-leva-indenizacao-757174734.aspAcesso: 20 ago 2009.

JUSTIÇA manda Ambev indenizar funcionário com R\$70 mil por humilhação. Folha online. 18 dez 2006. Disponível em: http://www1.folha.uol.com.br/folha/dinheiro/ult91u113190.shtmlAcesso: 13 set 2010

LEYMANN, Heinz. The content and development of mobbing at work. European Journal of Work and Organizationa Psychology, v. 5, n.2, p. 165-184, 1996.

LEYMANN, Heinz .Mobbing and Psychological Terror at Workplaces. ViolenceandVictims. v. 5, n. 2, 119-126, 1990.

LIMA Fo., Francisco das C.O assédio moral nas relações laborais e a tutela da dignidade humana do trabalhador. São Paulo: Ltr, 2009.

MAGALHÃES, Renan. Liminar proíbe Samsung de maltratar os funcionários. Correio Popular. Caderno Economia, p. B-14, 11 dez 2010.

NASCIMENTO, Sônia Mascaro. Assédio Moral. São Paulo: Saraiva, 2009.

PACHECO, Paula. Assédio moral assombra a LG. 0 Estado de São Paulo. 08 fev2010. Disponível em:

http://www.estadao.com.br/estadaodehoje/20100208/not_imp507902,0.php Acesso em: 08 ago 2010.

SCHATZMAN, M.; GOSDAL, T.C.; SOBOLL,L.A.; EBERLE, A.D. Aspectos definidores do Assédio Moral. In: GOSDAL, T.c. e SOBOLL, L.A.P.(Orgs) Assédio Moral Interpessoal e Organizacional. São Paulo: LTC 2009.

SOUZA, Jorge Dias. As chefias avassaladoras: a face oculta da tirania e do assédio moral nas empresas e o que fazer para acabar com essa prática devastadora. Osasco/SP: Novo século editora, 2009.

THOME, Candy F. 0 assédio moral nas relações de trabalho. São Paulo: Ltr, 2009.

WEBER, Max. Economia e sociedade. Brasília: Editora UNB, 1991.

ZAPF, Dieter. Organizational, work group related and personal causes of mobbing/bullying at work. International Journal of Manpower, v. 20, 1999.

ZULINO, Paulo R. Trabalhar fantasiado rende indenização, decide TST. o Estado de São Paulo. 31 mar 2008. Disponível em: http://www.estadao.com.br/noticias/economia,trabalhar-fantasiado-rendeindenizacaodecide- tst,148646,0.htm. Acesso em: 08 ago 2010 